\title{
POVOS INDÍGENAS NO RIO GRANDE DO NORTE, DIREITOS E AÇÕES EM TEMPOS DE COVID-19
}

\author{
ALLYNE DAYSE MACEDO DE MOURA ${ }^{1}$ \\ $M P F, B R A S I L$ \\ https://orcid.org/0000-0001-5924-5086 \\ LUÍS DE CAMÕES LIMA BOAVENTURA ${ }^{2}$ \\ $M P F, B R A S I L$ \\ https://orcid.org/0000-0001-6339-2900 \\ RITA DE CÁSSIA MARIA NEVES ${ }^{3}$ \\ $U F R N, B R A S I L$ \\ https://orcid.org/0000.0003-0507-8336
}

\begin{abstract}
RESUMO: Esse trabalho se propõe a pensar as politicas públicas de saúde no campo da atenção diferenciada em relação à população indígena no Rio Grande do Norte, tendo como referência os atos, processos e ações impetradas pelo Movimento Indígena e pelo Ministério Público Federal, como forma de acessar os direitos e a vacinação contra a Covid-19 no estado. Para tanto, situamos historicamente a construção das políticas de saúde indígena no Brasil, para em seguida apresentar como os indígenas do Rio Grande do Norte ainda não são considerados em suas especificidades étnicas em vários campos do direito, inclusive no acesso às políticas de saúde diferenciadas - apesar de mais de 20 anos de implementação no âmbito do Sistema Único de Saúde - o que se reflete nas dificuldades para serem inseridos como grupo prioritário no Plano Nacional de Vacinação. Apresentaremos também as ações e processos acionados, bem como os caminhos que os povos indígenas trilharam no estado para terem seus direitos respeitados. Para finalizar, retomamos alguns temas que estão na base das dificuldades tratadas ao longo do texto e que precisam ser enfrentados na execução de políticas públicas especificas direcionadas a essa população.
\end{abstract}

PALAVRAS-CHAVE: saúde indígena, covid-19, atenção diferenciada.

ABSTRACT: This work proposes to think about public health policies in the field of special attention related to the indigenous population in Rio Grande do Norte, taking as a reference the acts, processes and actions filed by the Indigenous Movement and the Federal Prosecution Service, as a way of accessing their rights and vaccination against Covid-19 in the state. Therefore, we historically situate the construction of indigenous health policies in Brazil, and then to present how the indigenous people of Rio Grande do Norte are still not considered in their ethnic specificities in many fields of law, including the access to differentiated health policies despite more than 20 years of implementation within the Unified Health System - which is reflected in the difficulties to be included as a priority group in the National Vaccination Plan.

\footnotetext{
${ }^{1}$ Mestre em Antropologia pela UFRN e assessora do Ministério Público Federal no Rio Grande do Norte. E-mail: allynemacedo2@gmail.com

${ }^{2}$ Mestrando em Direito pela UnB, especialista em direito público pela Escola Superior do Ministério Público da União e Procurador da República no Rio Grande do Norte. E-mail: camoes_boaventura@yahoo.com.br

${ }^{3}$ Doutora em Antropologia Social pela UFSC. Professora Associada do DAN/PPGAS/UFRN. E-mail: rita.neves@ufrn.br
}

MOURA, Allyne Dayse Macedo De; BOAVENTURA, Luís De Camões Lima; NEVES, Rita De Cássia Maria. Povos indígenas no Rio Grande do Norte, direitos e ações em tempos de covid-19. Espaço Ameríndio, Porto Alegre, v. 15, n. 2, p. 119145, mai./ago. 2021. 
Espaço Ameríndio

We will also present the actions and processes triggered, as well the ways that indigenous people token in the state to have their rights respected. Finally, we return to some themes that are at the base of the difficulties dealt with in the text and that need to be faced in the execution of specific public policies aimed to this population.

KEYWORDS: indigenous health, covid-19, special attention. 
Lo más importante que aprendimos de Foucault es que el cuerpo vivo (y por tanto mortal) es el objeto central de toda política. Il n'y a pas de politique qui ne soit pas une politique des corps (no hay política que no sea una política de los cuerpos).

Paul Preciado (2020)

Em 2018, quando estávamos na iminência de ser assaltados por uma situação nova no Brasil, me perguntaram: "Como os índios vão fazer diante de tudo isso?". Eu falei: "Tem quinhentos anos que os índios estão resistindo, eu estou preocupado é com os brancos, como vão fazer para escapar dessa".

Ailton Krenak (2019)

Esse texto foi construído na interface de duas áreas de conhecimento: o direito e a antropologia. Seu objetivo é, a partir de dados e documentos coletados, pensar o acesso às políticas públicas de saúde da população indígena no Rio Grande do Norte, tendo como referência a vacinação contra a Covid-19 no estado. Para isso, inicialmente apresentaremos de forma resumida o histórico e os dispositivos legais em relação ao direito à saúde diferenciada indígena no Brasil. Esta apresentação sucinta do tema visa situar a construção das políticas públicas de atenção à saúde indígena de forma ampla, para que, em seguida, possamos compreender a realidade específica dos povos indígenas no Rio Grande do Norte em relação ao não acesso a essas políticas de "atenção diferenciada" e o seu contexto local de luta para terem acesso à vacina.

Entre os materiais que embasam as reflexões aqui expostas, além da experiência de campo dos autores em espaços de articulação e reivindicação do Movimento Indígena, destacamos a Ação Civil Pública no 0800391-62.2020.4.05.8400, que trata da assistência à saúde prestada às Comunidades Indígenas no estado, e o Inquérito Civil $\mathrm{n}^{\mathrm{o}}$ 1.28.000.000709/2020-2, em trâmite no $12^{\circ}$ ofício da Procuradoria Federal do Rio Grande do Norte (PR/RN), que visa o monitoramento conjunto de ações e protocolos contra transmissão da Covid-19 entre os povos indígenas, tendo sido analisados os documentos acostados aos autos dos referidos processos. Vale salientar que esse texto, mais do que debater teoricamente a saúde indígena, propõe-se a refletir sobre a luta do Movimento Indígena no estado para se fazer presente e ter acesso aos direitos específicos já em implementação, ainda que de forma precária, para grande parte dos indígenas da região Nordeste do Brasil. Esse material também nos ajuda a pensar sobre os retrocessos na política 
indigenista como um todo e a importância de pesquisas que analisem o contexto de vulnerabilidade dessa população em situação de pandemia.

\section{Direito à saúde diferenciada no Brasil: histórico e dispositivos legais}

Ao lado da proteção das terras tradicionais, o serviço de saúde é uma das políticas públicas mais importantes de proteção aos povos indígenas. É garantia de sobrevivência física e cultural dessas populações, em um contexto no qual a letalidade de doenças e as dificuldades para atendimento e socorro causam aos indígenas mortalidade acima da média da população brasileira. Problemas relacionados à saúde se apresentam como o primeiro fator do decréscimo das populações indígenas (VILLARES, 2009).

Conforme definido pela Organização Mundial de Saúde (OMS), o conceito de saúde refere-se não apenas à ausência de doenças, mas ao bem-estar físico, mental e social completo. Em nossa sociedade, isso implica o acesso a um conjunto de condições necessárias, tais como renda, moradia, alimentação, saneamento, meio ambiente, trabalho, educação, esporte, lazer, acesso a bens e tratamento médico-hospitalar, sempre respeitando as decisões dos grupos sociais em acessar ou não determinadas políticas públicas. A saúde é um direito fundamental do ser humano que se relaciona com diversos outros direitos, conforme determinado em documentos de conferências e acordos assinados pelo Brasil - entre eles, no campo da saúde, temos a conferência de Alma-Ata, de 1978, realizada na URSS, que foi um marco importante e apontou diretrizes na efetivação de uma atenção primária à saúde. (DECLARAÇÃO DE ALMA-ATA, 1978).

As intensas mobilizações em torno da questão sanitária no Brasil, iniciadas na década de 1960, levaram no final da década de 1980, a diretrizes de descentralização, controle social e integralidade das ações de saúde, as quais refletiram também nas discussões sobre saúde indígena. Entre 1986 e 1993, foram realizadas várias conferências nacionais de saúde e encontros nacionais específicos sobre a saúde dos povos indígenas. O atual modelo de organização dos serviços de saúde para os povos indígenas nasceu, pois, nesse contexto de movimento por uma reforma sanitária, marcando um novo momento da participação na formulação das políticas públicas e assistenciais para a saúde indígena (FARIAS, 2011).

A Conferência Nacional de Proteção à Saúde do Índio, realizada em 1986 (BRASIL, 1986), constituiu um importante espaço no qual, pela primeira vez, o Estado brasileiro reuniu representantes de várias etnias indígenas, além de órgãos públicos e organizações da sociedade civil que atuam em apoio à causa indígena, para discutir uma proposta de diretrizes relativas à saúde indígena, assumido como dever do Estado a garantia da participação dos povos indígenas na construção, gestão e controle das ações e serviços de saúde, bem como reconhecendo como legítimas as necessidades e especificidades etnoculturais e geográficas dessas populações. 
Essa primeira Conferência Nacional deliberou sobre a responsabilidade da União para implementação da atenção à saúde indígena, bem como afirmou a necessidade desta política ser gerida por um único órgão, vinculado ao Ministério da Saúde e com representação indígena, garantindo a integração do sistema específico com o sistema nacional. Também afirmou a centralidade do controle social e a necessidade de políticas que acolham as formas diferenciadas das etnias indígenas no cuidado com a saúde. Além disso, apontou para a criação de um sistema de informação capaz de coletar e processar, de forma regular, os dados necessários a uma análise epidemiológica para retratar a dinâmica populacional, levando em conta a especificidade de cada povo.

Em 1988, a Constituição da República do Brasil (art.198) estabeleceu um novo regime de saúde pública no país, constituindo o Sistema Único de Saúde (SUS) - ainda pendente de aplicação em sua integralidade e que nasceu sem dotação orçamentária específica -, cujas ações e serviços públicos integram uma rede regionalizada e hierarquizada, organizadas a partir das seguintes diretrizes: i) descentralização com direção única em cada esfera de governo; ii) atendimento integral, com prioridade para as atividades preventivas, sem prejuízo dos serviços assistenciais; e iii) participação da comunidade (BRASIL, 1988). No entanto, a Lei $n^{\circ} 8.080$ de 1990, que regulamenta a organização e o funcionamento do SUS, inicialmente não teve qualquer atenção com a implementação de uma política diferenciada de saúde destinada aos povos indígenas.

Buscando superar essa lacuna, a Il Conferência Nacional de Saúde para os Povos Indígenas realizada em 1993 (BRASIL, 1993), com ampla participação das populações indígenas, construiu um modelo de saúde diferenciado a ser implementado a partir da criação de um subsistema de atenção à saúde, específico para atender aos povos indígenas. Através da lei no 9.836/1999, foi estabelecido o Subsistema de Atenção à Saúde dos Povos Indígenas (SasiSUS), passando a gestão da saúde indígena da Fundação Nacional do Índio (FUNAI) para a Fundação Nacional de Saúde (FUNASA). O Subsistema nasce vinculado ao SUS e baseado na estratégia administrativa de ação a partir da criação dos Distritos Sanitários Especiais Indígenas (DSEIs), como forma de garantir aos povos indígenas o direito ao acesso universal e integral à saúde a partir de suas necessidades e especificidades culturais, bem como envolvendo a participação dessa população em todas as etapas do processo de planejamento, execução e avaliação das ações de assistência à saúde ${ }^{4}$.

Mais três conferências se seguiram como forma de aperfeiçoar o SasiSUS, seja na sua estrutura administrativa, seja incorporando as reivindicações e mobilizações das populações indígenas em relação ao acesso, controle e financiamento da atenção diferenciada. Mesmo assim, após várias críticas à maneira como foram implementadas as ações nos

\footnotetext{
${ }^{4}$ Muitos trabalhos na antropologia têm sido publicados ao longo dos anos de implementação do SasiSUS. Em sua grande parte, apontando os problemas na execução das políticas de atenção diferenciada. Essa discussão não cabe nesse artigo, mas para um maior detalhamento, ver Langdon e Cardoso (2015); Langdon e Garnelo (2017); Diehl e Langdon (2015); Cardoso (2014); Garnelo (2014), entre outros.
} 
estados e municípios, principalmente por causa dos inúmeros conflitos locais entre índios e gestores, em 2010, como uma demanda advinda dessas conferências de saúde, foi criada a Secretaria Especial de Saúde Indígena (SESAI), órgão ligado diretamente ao Ministério da Saúde e de caráter executivo.

Os 34 Distritos Sanitários Especiais Indígenas, criados ainda dentro da estrutura da FUNASA, foram vinculados à SESAI. Estes permaneceram divididos estrategicamente por critérios epidemiológicos, étnicos e territoriais, tendo como base a ocupação geográfica das comunidades indígenas, não obedecendo assim aos limites dos estados. Sua estrutura de atendimento na Atenção Primária, conta com Unidades Básicas de Saúde indígenas dentro das aldeias, nos Polos Bases, com atendimento através das Equipes Multidisciplinares de Saúde Indígena (compostas por médicos, enfermeiros, agentes indígenas de saúde, agentes indígenas de saneamento, técnicos de enfermagem, odontólogos, entre outros) e com acompanhamento dos Conselhos Locais de Saúde. Além disso, outras estruturas auxiliam o atendimento à essa população, como as Casas de Apoio à Saúde Indígena (CASAI), que recebem os indígenas para o atendimento de média e alta complexidade, bem como realizam atendimento aos indígenas que estão momentaneamente nas cidades.

Especificamente a IV Conferência Nacional de Saúde dos Povos Indígenas, realizada em 2006 (BRASIL, 2006), destaca-se nesse texto por ter retomado as reivindicações quanto à reestruturação/reorganização dos DSEls para transformá-los em unidades gestoras, com autonomia política, financeira e administrativa, extensiva aos Pólos Base, garantindo em sua organização a participação de representantes indicados pelos povos indígenas, submetidos ao controle social, bem como com a estruturação dos Distritos sanitários a partir da aquisição de equipamentos necessários à atuação multiprofissional e meios de transporte que facilitem o acesso dos indígenas e dos profissionais de saúde aos espaços de atendimento.

Essa Conferência reafirmou a necessidade de atenção à saúde dos indígenas que vivem fora de seus territórios e dos povos em demanda de reconhecimento, apontando para que fossem respeitados os direitos dessas populações, inclusive quanto ao atendimento à saúde, independentemente das condições de demarcação ou não de seus territórios ou mesmo de outras condições de discriminação e sonegação de direitos. Igualmente destacou a demarcação e proteção dos territórios indígenas como condição indispensável à melhoria da saúde e da vida dessa população. O espaço construiu ainda outras propostas visando à garantia da proteção às terras indígenas; segurança alimentar; ampliação da participação da mulher indígena na atenção à saúde e no controle social; respeito às práticas tradicionais de cura e de autocuidado; ética nos estudos e pesquisas aplicados às demandas dos povos indígenas, assim como o fortalecimento da participação e controle social.

Conforme Mendes, Leite, Langdon e Grisotti (2018), quando comparados aos dados disponíveis para o restante da população brasileira, são evidentes as desigualdades que persistem após quase duas décadas de existência do subsistema de atenção à saúde indígena. A 
maioria das etnias indígenas ainda se encontra submetida à situação precária em termos de acesso aos serviços de saúde. Sabemos o quanto essa atual estrutura da SESAI ainda é deficitária e das discrepâncias de implementação dos Conselhos Distritais de Saúde Indígena (CONDISI) e dos demais segmentos administrativos. No entanto, é um sistema pensado ao longo desses anos, desde a sua criação, com a participação indígena e, de certa forma, apesar dos problemas apresentados e com os quais concordamos, é contundente entre os pesquisadores e indígenas a reafirmação da importância do mesmo enquanto modelo de atenção primária à saúde e da necessidade de ampliar e estruturar melhor o sistema.

Esses problemas apontados por indígenas e pesquisadores, diante dos limites na implementação da política nacional de atenção à saúde diferenciada, persistem em todas as regiões do país, sendo agravados em contextos nos quais as etnias vivenciam a invisibilidade e/ou negação de sua identidade indígena, o que obstaculiza ainda mais o acesso aos seus direitos - dentre eles a saúde diferenciada, como veremos a partir da realidade do Rio Grande do Norte (RN).

\section{Impactos da ausência de política de saúde para os Povos Indígenas do Rio Grande do Norte no atual contexto de pandemia}

O Rio Grande do Norte foi uma das primeiras áreas colonizadas e ainda hoje as populações indígenas que habitam seu território experimentam sérias dificuldades de reconhecimento, mesmo após mais de três décadas de vigência da Constituição de 1988, que inovou no ordenamento jurídico nacional e traz como um de seus pressupostos 0 marco da plurietnicidade da sociedade brasileira. No entanto, desde já registramos: a retórica constitucional está longe de uma satisfatória implementação prática. Como bem enfatiza Alcida Rita Ramos (2012, p. 12), "um dos talentos mais exercitados pelos Estados-Nações desta nossa América é a destreza na prestidigitação de criar constituições e burlá-las ao mesmo tempo".

Com base nos escritos de alguns autores (LIMA, 1990; CASCUDO, 1984; MEDEIROS FILHO, 1984; 1987; 1988), representantes de uma historiografia tradicional, por muito tempo foi disseminada a imagem de que todas as populações indígenas que habitavam o estado do Rio Grande do Norte teriam sido completamente exterminadas fisicamente ou assimiladas ao modo de vida do Brasil não indígena. Eloy Terena e Débora Duprat (2021) elucidam como a inferiorização dos povos originários da América e "a violência do projeto colonial, com morte, desterritorialização e captura de modos de vida, vão alimentar, em larga medida, as teorias raciais do século XIX e a própria formação dos Estados nacionais, com a noção de homogeneidade que lhe é correlata". Tal perspectiva sobre os povos indígenas expressa o que Pablo Gonzáles Casanova (2007) cunhou de colonialismo interno, categoria analítica que busca explicar fenômenos sociais derivados dos processos de conquista em que os povos nativos, 
minorias ou nações colonizadas são invisibilizados e subalternizados pelo Estado-Nação.

No RN, a "Guerra do Açu" ou "Guerra dos Bárbaros", como ficou nacionalmente conhecida, protagonizou uma série de confrontos entre índios e colonizadores no Nordeste do Brasil entre os anos de 1650 e 1720, reforçando no imaginário popular contemporâneo o marco desse extermínio indígena no estado. No entanto, a noção de extermínio total não se sustenta quando considerada a agência dos povos indígenas e suas estratégias de resistência, conforme evidenciam mais recentemente diversos pesquisadores (LOPES, 2003; MACEDO, 2011 ; SANTOS JUNIOR, 2008; CAVIGNAC, 2003) que, ao revisarem a historiografia tradicional, buscaram superar as lacunas na história do estado, sobretudo no que diz respeito aos índios do Rio Grande do Norte, que por muito tempo foram relegados às categorias genéricas de "caboclos", "mestiços" e até "desaparecidos" (GUERRA, 2011). Ademais, a partir do final do século XX e início do século XXI, essas etnias indígenas até então tidas como "desaparecidas", passaram a se reorganizar enquanto povo, acionando a sua história e memória, como forma de reafirmar suas identidades indígenas e forjar uma intensa luta pela efetivação de seus direitos específicos $^{5}$. Isso faz parte de um movimento mais amplo em nível regional pois, conforme descreve Souza Lima (2015):

nas mesmas décadas de 1950/1960, os povos indígenas do Nordeste lutavam arduamente para se verem reconhecidos enquanto indígenas, já que, no pêndulo das imagens dominantes no Brasil e no exterior do que sejam as populações indígenas das chamadas "Lowlands South America", eles só poderiam ser os remanescentes dos verdadeiros índios. Em sua maioria sem domínio de suas línguas e falando português, acantonados em porções reduzidas de terras, em geral em regiões de antigos aldeamentos missionários no Brasil colonial que ao longo dos séculos nunca deixaram de ocupar, os povos indígenas do Nordeste têm buscado reconstruir sua cultura material, seus rituais, defrontando-se com o duplo preconceito da discriminação por serem indígenas e por serem considerados indígenas inautênticos. Suas lideranças reivindicaram ao longo de todo o século $X X$, em especial desde os anos 1920 quando a administração tutelar se estabeleceu no Nordeste, o reconhecimento de sua condição de indígenas e de seu direito às suas terras, em movimento próprio e independente do Estado ou de qualquer mediador não indígena (p.437-38).

Especificamente no Rio Grande do Norte, dados apresentados pela Articulação dos Povos Indígenas do Rio Grande do Norte (APIRN) e pela

\footnotetext{
${ }^{5}$ Diversos trabalhos antropológicos se debruçam sobre a temática indígena contemporânea no Rio Grande do Norte elucidando reflexões estruturadas a partir das experiências especificas de cada povo. Para auxiliar uma investigação mais ampla sobre a realidade indígena no estado, podemos citar: Guerra (2011), Moura (2019), Oliveira e Vieira (2016) Pereira (2015), Silva (2007), dentre outros.
} 
FUNAI, informam que o estado possui atualmente dezesseis comunidades indígenas assistidas pelo órgão indigenista oficial. Totalizam uma população de aproximadamente 6.867 indígenas, divididos em três etnias - Potiguara, Tapuia Tarairiú e Tapuia Paiacu -, espalhadas por onze municípios do território potiguar.

Todas essas movimentações refletem os avanços conquistados a partir da promulgação da Constituição Federal de 1988, baliza do rompimento do Estado brasileiro com 0 projeto integracionista/assimilacionista, baseado em teorias de aculturação, que vigorou nos períodos anteriores. O novo pacto constitucional, em sentido oposto, reconhece a sociedade brasileira como pluriétnica e pluricultural e estabelece a responsabilidade da União em proteger e respeitar as populações indígenas, seus territórios e modos de vida, dentre outras obrigações, selando o compromisso com o direito dessa população a manter suas organizações sociais, costumes, línguas, crenças e tradições, bem como o direito originário sobre as terras que tradicionalmente ocupam, conforme o art. 231 e 232 da CF/88.

Nesse contexto, embora ainda incompleta em termos de efetivação, a Constituição de 1988 contribuiu para a reorganização/territorialização dos povos indígenas, com a retomada de parte dos seus territórios tradicionais e maior participação e autonomia desses povos na construção de políticas públicas específicas para atender às suas necessidades, assim como fortaleceu a reafirmação de identidades étnicas historicamente perseguidas/apagadas em todo o país, a exemplo dos indígenas do Nordeste, de tal modo que "a politização do étnico aparece como parte elementar dos processos reivindicatórios dos povos indígenas, contrariamente ao que previa com a integração do índio genérico na sociedade envolvente" (ATHIAS, 2007). Ainda assim, conforme elucida Coimbra Jr. e Santos (2000), as características fenotípicas, como a cor da pele, ou a pertença a determinada etnia, podem estar associadas a uma determinada estrutura de classe ou padrão de hierarquias sociais, podendo limitar em muito as possibilidades de mobilidade social ascendente e, consequentemente, restringir o acesso a bens e serviços sociais, ainda que formalmente garantidos, como acontece com os povos indígenas.

No Rio Grande do Norte, essa exclusão é acentuada pela ausência de ações públicas articuladas e contínuas para correta divulgação e valorização das especificidades étnicas e garantia da efetivação dos compromissos constitucionais e internacionais estabelecidos, o que acaba por perpetuar preconceitos e estereótipos na visão da população em geral, a qual muitas vezes desconhece os processos históricos e a diversidade cultural que incluem a existência dos povos indígenas. Ademais, a despeito das diversas mobilizações das populações indígenas no estado para efetivação de seus direitos em nível local, regional e nacional, e mesmo com a presença e atuação do órgão indigenista oficial no estado, tudo isso ocorrendo de forma intensa há mais de uma década, ainda hoje há gestores, parlamentares e funcionários públicos que ignoram reiteradamente a presença indígena e/ou reproduzem práticas 
discriminatórias no ambiente institucional, rejeitando ou buscando invisibilizar as etnias como fundamento para negação de direitos.

Até o presente momento o estado não possui, por exemplo, nenhuma terra indígena demarcada, a despeito de todas as reivindicações nesse sentido, sendo uma das principais demandas do Movimento Indígena no RN, ao lado da educação escolar indígena e da atenção à saúde diferenciada. É relevante travar a discussão acerca da problemática das terras indígenas no Brasil, e em especial na região Nordeste na qual o processo de territorialização está intimamente ligado aos processos de reafirmação étnica dos povos indígenas na medida em que se relaciona diretamente com a sobrevivência física e cultural das etnias indígenas. Não é difícil, portanto, compreender as razões das precárias condições de saúde, dentre outros problemas que atingem os povos indígenas, sobretudo quando estão completamente à margem da política de regularização fundiária, como no caso do Rio Grande do Norte, de modo que a negligência na prestação de serviços a saúde é agravada pela ausência do direito ao território.

Após muitas reivindicações do Movimento Indígena no estado, houve a tentativa de implementação da Política diferenciada de Atenção à Saúde no Rio Grande do Norte, entre 2015 e 2018, por meio do Distrito Sanitário Especial Indígena Potiguara do estado da Paraíba. Em visita anterior ao início dos atendimentos, o DSEI-Potiguara/PB divulgou uma "Nota Técnica", datada de 12/09/2014, descrevendo que em nenhuma das comunidades indígenas visitadas existia qualquer espécie de tratamento de água, coleta de lixo e a destinação correta dos resíduos sólidos. Conforme relatado pelos técnicos do DSEI Potiguara, as péssimas condições de saneamento básico (até hoje persistentes) eram obstáculos à qualidade de vida da população indígena no estado, sujeitando-a à proliferação de diversas doenças.

Com efeito, as ações e políticas de saúde passaram a ser realizadas no Rio Grande do Norte apenas por uma Equipe Multidisciplinar de Saúde Indígena (EMSI), composta por 05 (cinco) profissionais, sendo um enfermeiro, um médico, um auxiliar de saúde bucal, um dentista e uma assistente social, cujo organograma previa a prestação de serviços uma vez por semana nas aldeias Catú, Lagoa do Tapará, Assú, Sagi Trabanda e Amarelão, além de atenderem aos indígenas Tabajara, no estado da Paraíba, seguindo o modelo de Estratégia de Saúde da Família (ESF) no âmbito do SUS. Em razão da inexistência de Unidade Básica de Saúde indígena (UBSI), os atendimentos seriam realizados nas UBS municipais ou por meio de visitas domiciliares.

Enquanto nos demais estados do Nordeste, cada povo indígena tem uma ou mais EMSI atuando nas aldeias, no Rio Grande do Norte apenas uma equipe atuava em todo o estado. Desse modo, a população não conseguia ser assistida pela equipe, que passava mais tempo em trânsito do que nas comunidades, sem contar os inúmeros problemas com o transporte para percorrer todo o estado e ainda atender aos índios Tabajara, na fronteira do estado da Paraíba. Além disso, em nenhuma das comunidades foram contratados Agentes Indígenas de Saúde (AIS) e menos ainda Agentes Indígenas de Saneamento (AISAN). 
Burocraticamente, como a legislação indicava, em 2015 foram criados dois Conselhos Locais de saúde no estado. No entanto, esses conselhos são mistos, com distintos povos participando. Ou seja, possuem apenas representação de cada etnia, o que significa que a preocupação do Conselho se dava sempre a nível do DSEI, que está instalado na Paraíba e não conseguiam tratar dos problemas da atenção básica local nas comunidades. Por causa da distância e diversidade de povos representados, os conselheiros só conseguiam se encontrar em outros eventos que não os da saúde, imobilizando a atuação na prática.

Em que pese a atuação do DSEI Potiguara, os indígenas do Rio Grande do Norte nunca foram devidamente cadastrados no Sistema de Informação da Atenção à Saúde Indígena (SIASI), permanecendo invisíveis para a Política de Saúde diferenciada. Como consequência, uma vez que o orçamento destinado ao DSEl é calculado de acordo com o número de indígenas cadastrados no SIASI, nunca foram destinados recursos próprios para atuação no Rio Grande do Norte, que dependia totalmente das verbas destinadas à população Potiguara da Paraíba. Além dos obstáculos à estruturação material/financeira, a ausência de cadastramento dos índios no SIASI impossibilitou diagnósticos e acompanhamentos fundamentais a qualquer política pública de saúde que vise atender a contento as necessidades das etnias indígenas, evidenciando o modo precário como a Saúde indígena foi ofertada no RN.

Da mesma forma, quase não ocorreu a conferência local de preparação para a VI Conferência Nacional de Saúde que estava prevista para acontecer em 2019. Após uma intensa mobilização da APIRN, a pré conferência ocorreu no auditório da biblioteca da Universidade Federal do Rio Grande do Norte (UFRN) em 2018. Na abertura do evento, a fala do coordenador do DSEI Potiguara causou polêmica logo no início ao dizer que "não adianta cadastrar o RN no SIASI, sem orçamento". Afirmou que foi cortado $15 \%$ do orçamento do DSEI Potiguara - então não era possível atender também ao RN e ainda ao povo Tabajara da Paraíba.

A enfermeira da equipe, que atuava no RN, falou logo em seguida e também foi enfática ao afirmar que "uma só equipe viajando os 6 (seis) municípios e visitando as 11 (onze) comunidades do RN é inviável". Na prática o que tudo isso gerou foi um intenso conflito entre os indígenas da Paraíba e os do Rio Grande do Norte, com a impressão de que o dinheiro que deveria ser aplicado apenas na Paraíba tinha que ser dividido com o Rio Grande do Norte. Disso se extrai que a omissão estatal, além de impor invisibilidade aos povos indígenas do $\mathrm{RN}$, repercute em conflito interétnico entre grupos que poderiam somar esforços por pautas comuns.

Todo esse cenário culminou no pedido de interrupção das ações de saúde oferecidas pelo DSEI Potiguara aos povos indígenas do Rio Grande do Norte e, assim, no início de 2019, esses povos saíram de uma situação de insuficiência para a completa ausência no que diz respeito à fruição regular do direito à saúde. A partir daí, o atendimento da política pública de saúde indígena deixou de ser efetivado, sem que nenhuma medida para suprir essa lacuna fosse tomada pela Secretaria Especial de Saúde Indígena (SESAI), estando as populações indígenas do RN à margem da 
Política Nacional de Atenção à Saúde diferenciada. Alguns exemplos recentes ilustram essa desassistência.

Antes mesmo das dificuldades agravadas pela pandemia atual, tivemos o exemplo da imunização referente à gripe H1N1. A população indígena é considerada grupo prioritário, no entanto, pela ausência da SESAI no estado, isso não tem ocorrido em todas as comunidades indígenas. A liderança Tayse Campos, pertencente ao grupo familiar Mendonça, da etnia potiguara, e representante do Fórum de lideranças indígenas, informou que alguns municípios, reconhecendo a presença de populações indígenas em sua circunscrição, solicitaram e realizaram campanhas de vacinações para esse público, mas, na maioria dos municípios onde há a presença indígena, a imunização foi feita apenas nos idosos, sem representar um atendimento específico para a população indígena. A liderança também relatou que nenhuma das comunidades indígenas do estado recebeu as carteiras que deveriam ter sido enviadas pelo Ministério da Saúde para acompanhamento da saúde dos indígenas idosos, bem como que seguem excluídas das ações voltadas para saúde gestacional e demais campanhas nacionais com foco na saúde da mulher indígena. ${ }^{6}$

Já em maio de 2020, durante o curso do Inquérito Civil $\mathrm{n}^{\circ}$ 1.28.000.000709/2020-2, em trâmite no $12^{\circ}$ ofício da PRRN, instaurado a partir de pedido dos Indigenistas Associados (INA), objetivando o monitoramento conjunto de ações de proteção territorial, segurança alimentar, auxílios e benefícios, insumos e protocolos contra transmissão da COVID-19 para todos os povos indígenas, o Ministério Público Federal (MPF), questionou a SESAl se os indígenas do Rio Grande do Norte estavam ou não cadastrados no SIASI e se estavam sendo atendidos pela Secretaria Especial. Além disso, questionou sobre o acompanhamento dos casos de COVID-19 contabilizados entre os indígenas do estado e, inclusive, inquiriu sobre quais providências estavam sendo tomadas na tentativa de minorar os efeitos da pandemia para essa população.

Em resposta, a SESAI confirmou a total inexistência de atenção à saúde indígena no Rio Grande do Norte, assim como afirmou que não possui nenhum indígena cadastrado como residente no estado. Em complemento, explanou que esses povos não se encontram aldeados, motivo pelo qual estariam fora do escopo legal de atuação da Secretaria. Além disso, informou que em virtude da não assistência dos indígenas do RN pelo órgão, os dados epidemiológicos da população indígena no estado são monitorados pelas secretarias municipais e estadual de saúde, na proporção em que os boletins epidemiológicos publicados diariamente pela SESAI dizem respeito apenas aos indígenas assistidos pelo SASISUS.

Por esse motivo, a Articulação dos Povos Indígenas do Rio Grande do Norte (APIRN), juntamente com a coordenação microrregional da Articulação dos Povos Indígenas do Nordeste, Minas Gerais e Espírito Santo (APOINME) começou em abril de 2020 a monitorar sistematicamente a situação de saúde nas aldeias e comunidades indígenas espalhadas pelo estado, seja por meio do registro dos dados

\footnotetext{
${ }^{6}$ Diálogo telefônico realizado em 28 de maio de 2021.

MOURA, Allyne Dayse Macedo De; BOAVENTURA, Luís De Camões Lima; NEVES, Rita De Cássia Maria. Povos indígenas no Rio Grande do Norte, direitos e ações em tempos de covid-19. Espaço Ameríndio, Porto Alegre, v. 15, n. 2, p. 119145, mai./ago. 2021
} 
epidemiológicos, seja no desenvolvimento de ações de prevenção e controle à saúde. A atuação da APIRN tem sido decisiva no contexto da pandemia, dada a subnotificação e ausência total de registros nos boletins da SESAI, como indicado acima. Além da falta de assistência, com o advento do Covid-19 essas populações ficaram ainda mais desassistidas por não serem contabilizadas e nem contempladas por uma atuação específica de combate à pandemia. Além disso, há ainda a ausência de dados qualificados nos boletins das secretarias municipais e estadual sobre a situação das aldeias e comunidades, bem como de indígenas que vivem fora de seus territórios.

Nesse contexto de adoção de estratégias locais para enfrentamento da pandemia é importante destacar o aumento do uso das ferramentas virtuais pelas lideranças indígenas para mobilização de recursos e divulgação das ações realizadas nessas comunidades, inclusive a criação da live Poty Papo na rede social Instagram, promovida pela APIRN e do site de acompanhamento da situação dos povos indígenas no estado organizado pelo professor Glebson Vieira, do PPGAS/UFRN, em parceria com a APIRN, e que está produzindo regularmente boletins sobre o tema desde junho de $2020^{7}$.

A situação dramática vivenciada pelos indígenas do Rio Grande do Norte ensejou, em junho de 2020, a Ação Civil Pública n ${ }^{\circ} 0800391$ 62.2020.4.05.8400, de autoria do Ministério Público Federal, pela garantia da assistência à saúde das comunidades Indígenas no Rio Grande do Norte. Por meio de decisão interlocutória, em fevereiro de 2021, o judiciário proveu parcialmente os pedidos do órgão ministerial determinando que a União, com auxílio da Funai, em até 180 (cento e oitenta) dias, a contar do final da situação de emergência de saúde pública decorrente do coronavírus (Covid-19), proceda com o cadastramento no SIASI de todos os índios das comunidades Mendonça do Amarelão, Serrote de São Bento, Eleotérios do Catu, Sagi/Trabanda, Tapuias de Tapará, Caboclos do Açu, que assim deseje e, anualmente, promova treinamentos para os profissionais de saúde dos municípios de João Câmara, Canguaretama, Baía Formosa, Macaíba e Açu, nos quais estão as comunidades indígenas contempladas pela decisão, de modo a capacitálos à prestação de serviços de atenção básica de saúde especializada para os indígenas locais.

Ocorre que, além de não contemplar todas as populações indígenas do estado, a decisão não resolve o agravamento da situação dos povos indígenas no atual contexto de pandemia pela Covid-19, compelindo o Movimento Indígena a buscar outros meios para a garantia emergencial do direito à Saúde, como as inúmeras campanhas de doação de alimentos, feiras solidárias, vakinhas, barreiras sanitárias, etc. Ao todo, de acordo com o último boletim publicado no site do CCHLA/UFRN, em março de 2021, tivemos no estado desde o início da pandemia, 5 óbitos e 95 e cinco casos confirmados. De acordo com as lideranças, só não houve mais casos de contaminação porque as comunidades se organizaram para

\footnotetext{
Para acompanhar os dados epidemiológicos dos indígenas no $\mathrm{RN}$, acessar: https://cchla.ufrn.br/povosindigenasdorn/covid.html 
conter o avanço da doença em suas aldeias, muitas vezes tendo que entrar em atrito com alguns indígenas que não concordavam com o confinamento.

Importante salientar que o Ministério da Saúde, no dia 16 de dezembro de 2020, por meio da Coordenação Geral do Programa Nacional de Imunizações - CGPNI e do Departamento de Imunização e Doenças Transmissíveis - DEIDT da Secretaria de Vigilância em Saúde SVS, apresentou o Plano Nacional de Operacionalização da Vacinação contra a Covid-19, estabelecendo três fases de vacinação prioritária, cada uma dedicada a grupos populacionais específicos. As prioridades foram ordenadas visando à preservação do funcionamento dos serviços de saúde e proteção dos indivíduos com maior risco de desenvolvimento de formas graves e óbitos, seguido do funcionamento dos serviços essenciais e proteção dos indivíduos com maior risco de infecção.

Apesar disso, em sua primeira fase, a listagem contemplava apenas indígenas aldeados em terras indígenas demarcadas - os demais foram excluídos do plano prioritário de vacinação, sendo ignorado o fato de que a ausência de demarcação territorial é um fator de vulnerabilidade, inclusive sanitária, das populações indígenas. Por outro lado, em julho de 2020, houve decisão do Ministro Luís Roberto Barroso (no âmbito da Medida Cautelar na Arguição de Descumprimento de Preceito Fundamental $n^{0}$ 709), confirmada no mês seguinte pelo Plenário do Supremo Tribula Federal (STF), por meio da qual, entre outros aspectos, foi determinada a imediata extensão dos serviços do Subsistema Indígena de Saúde aos povos aldeados situados em terras não homologadas e aos indígenas não aldeados quando verificada barreira de acesso ao SUS geral.

Ainda assim, o Ministério da Saúde seguiu omisso na garantia da imunização contra a COVID-19 aos povos indígenas que vivem em território não demarcado ou em áreas urbanas. Em reação, a Articulação dos Povos Indígenas do Brasil (APIB) peticionou ao Supremo Tribunal Federal (STF), em 28 janeiro de 2021, objetivando a vacinação de todos os indígenas do Brasil na primeira fase do plano de imunização, incluindo os não aldeados. Acionando os preceitos fundamentais da isonomia (art. $5^{\mathrm{a}}$, caput, CF/88), o direito fundamental à saúde (art. $6^{\circ}$ e 196) e à vida (art. $5^{\circ}$, caput) e também o direito dos povos indígenas a viverem de acordo com suas culturas e tradições (art. 231), foi denunciada pala organização a inconstitucionalidade da discriminação de determinados grupos indígenas por parte do Estado brasileiro em sua atuação sanitária.

$\mathrm{Na}$ ocasião, a APIB retomou as frases do Ministro Barroso, proferidas no Plenário da Corte, quando classificou como "inaceitável a postura da União com relação aos povos indígenas aldeados localizados em Terras Indígenas não homologadas" e afirmou que os "povos indígenas localizados em zona urbana também constituem povos indígenas e, nessas condições, gozam dos mesmos direitos de todo e qualquer povo indígena". A petição citava, inclusive, o exemplo do Rio Grande do Norte, vejamos: 
Não há, assim, qualquer justificativa possível para a exclusão dos indígenas residentes em áreas não demarcadas do grupo prioritário de vacinação para a Covid-19. A gravidade da conduta do governo federal na matéria fica muito evidente quando se observa que o Ministério da Saúde não destinou até o momento nenhuma dose de vacina para os indígenas do estado do Rio Grande do Norte, embora seja público e notório o fato de que os povos Potiguara e Tapuia habitam a região (APIB, 2021, p. 14).

Destaca-se que, até o final de fevereiro de 2021, o Rio Grande do Norte era o único estado do país a não ter vacinado nenhum indígena. Nas palavras do Cacique Dioclécio Mendonça, da etnia potiguara:

Isso só mostra a falha do governo federal porque os indígenas que estão em terras em processo de demarcação não têm culpa de suas terras ainda não serem demarcadas. [...] Então, como estaremos no nosso território demarcado, se a União não cumpre seu papel? No Rio Grande do Norte não temos nenhuma terra demarcada. Temos a aldeia de Sagi Trabanda, que está em processo de demarcação territorial e já tem um Grupo Técnico de Trabalho da Funai instituído, mas que está paralisado justamente pela ineficácia do atual presidente da Fundação Nacional do Índio, assim como o presidente da República não autoriza a homologação das terras indígenas em todo o país, o que causa esse entrave no processo de demarcação das terras. [...] Antes nós tínhamos o Atendimento Especial da Saúde Indígena, mas com o desmonte da Sesai não há mais essa assistência na unidade da Paraíba, o que causou reflexo nesse quantitativo de vacinação. A Sesai informou ao Ministério da Saúde que não havia indígenas aldeados no RN, o que é uma mentira! Somos 16 comunidades indígenas, sendo 15 em aldeamentos. Eu dou como exemplo Santa Teresinha, onde estão mais de 200 famílias indígenas. São mais de 840 pessoas morando na aldeia, assim como o território Mendonça é composto por seis aldeias indígenas localizadas na zona rural[...]" (MENDONÇA, 2021, np).

Diante da ausência da política nacional de saúde diferenciada, as lideranças indígenas e a CTL-FUNAI passaram a buscar construir uma articulação mais próxima com as instâncias de saúde em nível estadual e municipal visando um atendimento integral, qualificado e imediato das etnias indígenas durante a pandemia. Entretanto, tanto os indígenas quanto a comissão técnica local do órgão indigenista relataram as dificuldades desses diálogos, em razão das instâncias de saúde locais não possuírem propriedade de conhecimento para um adequado atendimento 
às populações indígenas, além das limitações de estrutura e quadro pessoal desses entes.

Nesse contexto de articulações políticas, as organizações indígenas e a FUNAI apresentaram junto ao Ministério Público Federal a reclamação pela inclusão de todas as comunidades atualmente autodeclaradas indígenas no Rio Grande do Norte na já citada Ação Civil Pública que busca a efetivação da Atenção à Saúde Indígena no estado, bem como demandaram do órgão ministerial as providências cabíveis para a imediata vacinação das populações indígenas do estado na primeira fase do plano de imunização contra a Covid-19. Nesse contexto, desabafou o Cacique Dioclécio "Já acionamos o Ministério Público, a $6^{\text {a }}$ Câmara e a todo momento dialogamos com a Funai com o intuito de que se cobre da SESAI a implantação de uma equipe multidisciplinar de saúde no estado, porque nossas demandas só seriam superadas na saúde com a implantação de um DSEl" (MENDOÇA, 2021 , np.).

Em 04 fevereiro de 2021 foi realizada uma reunião virtual com a participação da APIRN, FUNAI, SESAP/RN, Conselho Estadual de Saúde; do Conselho Estadual de Políticas de Promoção da Igualdade Racial (COEPPIR); da Secretaria de Estado das mulheres, da juventude, da igualdade racial e dos direitos humanos (SEMJIDH); da APOINME e da Associação Comunitária Indígena do Amarelão para tratar da ausência dos indígenas como grupo prioritário no plano de vacinação contra a Covid19 no Rio Grande do Norte. Na ocasião, conforme o Movimento Indígena, a SESAP/RN informou que oficiou o Ministério da Saúde e a SESAI sobre o equívoco de não ter sido considerada a população indígena do Rio Grande do Norte no plano de vacinação nacional - impossibilitando, assim, a sua inclusão no plano estadual -, bem como solicitando o envio das doses destinadas a essa população no próximo lote de vacinas a ser recebido pelo $\mathrm{RN}$, sem que houvesse tido resposta formal, até aquele momento, para resolução da questão. Essas mesmas informações constam no ofício $n^{\circ} 7 / 2021$ encaminhado pela FUNAl em Natal (CTL - FUNAI-Natal) à APIRN e juntado ao Inquérito Civil $\mathrm{n}^{0} 1.28 .000 .000709 / 2020-2$ PRRN, através do qual o órgão indigenista relata o conteúdo debatido em reunião anterior realizada entre a autarquia federal e a SESAP no dia 02 de fevereiro 2021.

Após reclamação da APIRN sobre os fatos supracitados, ainda em fevereiro, o Ministério Público Federal determinou, como diligência do Inquérito Civil correlato, que a FUNAl prestasse informações, dentre outras, quanto aos impactos da epidemia da Covid-19 sobre as populações indígenas do Rio Grande do Norte e sobre as políticas de saúde implementadas no estado. Dentre as informações apresentadas, a Comissão Técnica local do órgão indigenista elucidou que:

a pandemia pelo Covid-19 intensificou a situação de vulnerabilidade social dos povos indígenas do estado, uma vez que dificultou ou mesmo inviabilizou as atividades produtivas desenvolvidas pelas comunidades indígenas, com destaque para a venda de seus produtos nas feiras das cidades circunvizinhas e o beneficiamento 
da castanha de caju nas Aldeias que compõem o território indígena Mendonça. Com relação ao número de contaminação e óbitos de indígenas pela Covid-19, infelizmente não possuímos tais dados, tendo em vista a ausência da política da SESAI no estado potiguar [...] (BRASIL, 2021, p. 2).

Paralelamente, em resposta às mobilizações indígenas no estado, foram expedidos ofícios por parte da FUNAI, SESAP/RN e MPF à Secretaria de Vigilância em Saúde do Ministério da Saúde buscando correção do equívoco sobre a inexistência de indígenas no Rio Grande do Norte e cumprimento do envio das doses destinadas à vacinação dessa população na primeira fase do plano de imunização, conforme determinação legal. $\mathrm{Na}$ sequência, o Ministério da Saúde enviou o quantitativo de 2.920 (duas mil novecentos e vinte) doses destinadas à população indígena do estado, que começou a ser vacinada no dia 26 de fevereiro de 2021 .

Após correção do equívoco inicial, o Movimento Indígena precisou ainda denunciar a devolução de parte das vacinas destinadas à população indígena em razão do município de Natal, capital do estado, não ter reconhecido, quando do recebimento das doses, a presença indígena em sua circunscrição. Conforme manifestação subscrita pelo Cacique Dioclécio, em nome da APIRN, direcionada ao Ministério Público Federal:

Na cidade do Natal, 57 famílias estão distribuídas em bairros da Zona Norte, em razão das migrações ocorridas no ano de 1986 por causa dos abalos sísmicos que ocorreram no Município de João Câmara/RN. Essas famílias reivindicavam seu reconhecimento desde 2009, já tendo o reconhecimento pelo Fórum de Lideranças Mendonça, e desde os anos 2019 vem sendo assistidas pela FUNAI. Apesar disso, a Prefeitura do Natal devolveu as vacinas enviadas pelo Ministério da Saúde para os indígenas que vivem na capital potiguar, afirmando não reconhecer a população indígena em seu território. Diante desse absurdo, que se revela como mais uma grave violação aos direitos dos povos indígenas do Rio Grande do Norte, solicito providências do MPF (MENDONÇA, 2021, p. 1).

Diante disso, o órgão ministerial expediu recomendação ao Secretário de Saúde do Município de Natal para que se retratasse e providenciasse a imediata devolução das vacinas contra Covid-1 9 para os povos indígenas que vivem em Natal, efetivando a devida imunização, tendo o recomendado sido atendido pela SMS-Natal.

No entanto, mesmo após o início da imunização indígena no RN, lideranças indígenas e a mídia local relataram episódios de racismo por parte de gestores e profissionais das equipes de vacinação em diversos municípios, por afirmações de que não existiam índios no estado ou que indígenas estariam falsamente alegando sua identidade indígena para serem imunizados ou, ainda, que não deveriam ter prioridade por viverem 
fora das aldeias, fazendo com que as populações precisassem mais uma vez reafirmar publicamente sua história, memória e identidade indígena para demonstrar a legitimidade de seus direitos ainda tão longe de serem completamente efetivados.

Francisca Bezerra, Cacique do Povo Tapuia da Lagoa do Tapará e coordenadora da Microrregional da APOINME no RN, por meio de diálogo telefônico em 08 de abril de 2021, relatou ter recebido informações de que coordenadores de saúde estariam fazendo tais afirmações com relação à sua comunidade e, diante disso, afirmou: "Eu achei um absurdo, eu acho que isso é racismo. É racismo institucional e alguém deve responder por isso. É uma falta de respeito e grande. Pode ser por inocência ou por não conhecer? Pode. Mas por isso mesmo, a gente não deve falar o que não sabe".

Em contexto semelhante, o Centro Histórico Cultural Tapuias Paiacus da Lagoa do Apodi, por meio de Nota de Repúdio publicada nas redes sociais, na qual respondia às manifestações de um parlamentar, lembrou que nenhuma das 16 comunidades autodeclaradas indígenas no estado tem seus territórios demarcados e que, por isso, em um primeiro momento, foram excluídas do processo de vacinação contra a Covid-19, uma vez que o plano divulgado pelo governo federal inicialmente incluía somente os "índios aldeados". A nota apontou a problemática dessa categoria por remeter ao regime de exceção dos militares que vigorou antes da promulgação da Constituição Federal de 1988, e destacou que a situação foi revertida para garantia da imunização prioritária dos indígenas por consequência da luta de suas organizações. O texto destaca que: "Os índios que estão nos centros urbanos têm como um dos motivos para estarem nestes espaços a expulsão dos seus territórios por invasores, logo, é um ato de extrema violência [...] O fato de o indígena estar fora da aldeia e viver na cidade não faz com que ele deixe de ser indígena" (CHCTPLA, 2021 , np).

A partir desses fatos, a CTL-FUNAl encaminhou ofício ao MPF solicitando o acompanhamento na distribuição das vacinas e do processo de imunização dos povos no estado, pontuando ainda a demora para aplicação das doses por parte de alguns dos municípios nos quais estão as comunidades indígenas. Além disso, a autarquia indigenista relatou suas preocupações diante da falta de informações sobre a disponibilidade de novas doses para os indígenas no estado, tendo em vista que o quantitativo de vacinas direcionadas até então não foi suficiente para imunizar a totalidade da população indígena acima de 18 anos no Rio Grande do Norte.

Diante disso, o $12^{\circ}$ ofício da PR/RN expediu recomendação dirigida ao Secretário de Saúde do Estado do Rio Grande do Norte para que, no prazo máximo de 5 (cinco) dias, solicitasse ao Ministério da Saúde a complementação das doses necessárias para imunizar a totalidade dos povos indígenas do RN contra a Covid-19; Ao Secretário de Vigilância em Saúde do Ministério da Saúde, para que enviasse, com urgência, as referidas doses e aos Secretários de Saúde dos municípios localizados na área de atuação do referido ofício, quais sejam: Baía Formosa, Goianinha, Canguaretama, Macaíba, São Gonçalo do Amarante e Natal, nos quais 
estão localizadas partes das comunidades indígenas do estado, para que: a) fossem respeitados os processos de autorreconhecimento dessas populações, bem como seus processos e organizações sociais; b) que, após recebimento das doses destinadas aos povos indígenas, fosse efetivada com celeridade sua imunização; e c) que fosse realizada articulação com os Centros de Referência de Assistência Social - CRAS e lideranças indígenas, para desenvolvimento de um trabalho de informação junto às famílias indígenas antes da chegada da equipe de vacinação, sobre a segurança da vacina, importância para saúde e a forma de aplicação, com o devido respeito à sua cultura e participação nos processos de tomada de decisão. Cópias da recomendação foram remetidas às Procuradoria da República nos municípios de Assú, Mossoró e Ceará-Mirim, nas quais estão localizadas as demais comunidades indígenas do estado.

Apesar da resposta positiva de alguns municípios, confirmada pelos indígenas interessados, quanto ao cumprimento da supracitada recomendação, outros afirmaram a continuidade da impossibilidade de imunização total de sua população indígena contra a Covid-19 em razão da insuficiência das doses recebidas. Assim, até o presente momento, o Movimento Indígena segue reivindicando às autoridades a garantia plena desse direito.

Vale destacar, ainda, que a Secretaria Municipal de Saúde de Natal oficiou o Ministério Público Federal solicitando orientações diante de dúvidas que surgiram no processo de imunização dos povos indígenas no atual contexto de Pandemia. O documento, juntado ao Inquérito Civil $n^{\circ}$ 1.28.000.000496/2020-37, em trâmite no $10^{\circ}$ Oficio da PR/RN, questionava sobre a possibilidade de ser requisitado aos indígenas documento comprobatório de sua identidade, bem como se existia um modelo específico para essa autodeclaração ou se poderia ser escrito a próprio punho. Também questionava se, ao invés da autoidentificação individual, poderia o representante da etnia indígena apresentar uma lista informando o reconhecimento de sua população indígena, bem como se este documento poderia ser entregue aos profissionais de saúde para ser anexado ao cadastramento dos indígenas usuários da saúde pública no município.

Em sede de resposta, o MPF informou sobre a inexistência de documento específico para comprovação da identidade indígena, bem como que, para fins administrativos, os gestores públicos podem fazer o registro da autodeclaração de forma escrita ou não, a depender da realidade de cada povo indígena, tendo em vista que nem todos os indígenas são alfabetizados ou falam a língua portuguesa. Nesse mesmo sentido, afirmou como legítima a apresentação de lista por parte das organizações indígenas reconhecendo indivíduos como pertencentes à sua etnia, se assim acharem conveniente, desde que isso não limite ou exclua autodeclarações que venham a ocorrer em paralelo ou a posteriori.

As sucessivas situações vivenciadas pelos povos indígenas na busca pelo direito à saúde evidenciam que o desconhecimento sobre as questões que envolvem as especificidades étnicas e os direitos das populações indígenas ainda se perpetua, sobretudo nas instituições 
públicas no Rio Grande do Norte. Ademais, revelam a invisibilidade jurídica que o Estado brasileiro ilegalmente impõe aos povos indígenas que vivem no território potiguar, uma vez que os dados populacionais desse grupo, a rigor, deveriam estar disponíveis nos bancos do SIASI, do Ministério da Saúde, para subsídio das ações de atenção à saúde indígena no RN e, em especial, nos municípios onde há presença indígena, conforme destacado na supracitada resposta do MPF à SMS/Natal.

Não bastassem as dificuldades próprias do contexto pandêmico, do agravo das situações de vulnerabilidade anteriores e dos limites da efetivação da saúde indígena que enfrentam todos os povos indígenas no país, resta evidenciado que no território potiguar esse contexto é aprofundado pela necessidade de, a despeito de toda legislação sobre a temática, a todo instante os indígenas precisarem comprovar sua existência perante o poder público, algo que vem sendo feito das mais variadas formas pelo Movimento Indígena no estado há mais de uma década e que já deveria ter sido resolvido desde a constituição de 1988.

Inquestionavelmente, a crise provocada pela pandemia de Covid-19 destaca a vulnerabilidade política, social, ambiental e sanitária dos povos indígenas do Rio Grande do Norte. As novas disputas enfrentadas pelos indígenas em torno do reconhecimento de suas especificidades para garantia do direito à saúde em nível local e federal, em especial na busca pela imunização de sua população nesse contexto pandêmico, enseja ações de reafirmação das identidades étnicas, reorganização das articulações políticas e contínuas reivindicações aos órgãos de proteção aos direitos indígenas, evidenciando não somente os impactos, como também as modalidades de resistência e enfrentamento do movimento etnopolítico indígena, que segue reafirmando a existência de sua população para efetivação dos seus direitos.

\section{Questões e dilemas: Considerações finais?}

Para encerrar esse texto, mas não a discussão, gostaríamos de refletir a partir de três eixos que emergiram das questões apresentadas acima: a dimensão social das desigualdades, as políticas públicas de saúde e o papel do Estado e a agência desses indígenas em situação de pandemia do Covid-19.

Há efetivamente no Brasil uma distinção entre a garantia jurídicopolítica de um direito e sua efetivação prática. A contínua luta dos povos indígenas do Rio Grande do Norte pela efetivação do direito à Saúde, ao longo dos anos, e os impactos da ausência de uma política de saúde diferenciada no atual contexto de pandemia, em especial obstaculizando a vacinação na primeira fase do plano nacional de imunização contra a Covid-19, é resultado de um processo mais amplo de discriminação institucional que se reflete na restrição de acesso a políticas públicas e em violações aos diversos direitos dessa população. Quando no início da pandemia se falava que o vírus não tem classe nem raça nos fez pensar que estávamos juntos na luta pela saúde da humanidade como um todo. Aos poucos, fomos identificando que há uma dimensão social das 
desigualdades que se apresentam nas dificuldades de acesso às políticas públicas mitigadoras dessa realidade.

Embora os problemas para efetivação dos direitos indígenas não sejam um fato isolado, e sim, de repercussão nacional, os Povos Indígenas do Rio Grande do Norte, como pudemos observar nas situações expostas, vivenciam uma série de dificuldades mais amplas para acesso às políticas públicas direcionadas à essa população específica. A primeira delas, a negação ainda hoje da presença indígena no estado, seja por desconhecimento ou por má-fé, fazendo com que esses indígenas precisem o tempo todo reafirmar sua existência, para em seguida poder discutir com o Estado as políticas específicas que por direito Ihes são devidas.

Mesmo quando reconhecida essa existência, afinal estamos falando de mais de uma década de mobilizações e da afirmação organizada e articulada dessa especificidade por parte das etnias indígenas do Rio Grande do Norte, ainda assim, o desconhecimento acerca dos dispositivos legais que versam sobre os povos originários é marcante na atuação dos gestores e funcionários públicos em nível local e regional, inclusive com relação à Convenção $\mathrm{n}^{0} 169$ da OIT, instrumento jurídico basilar e largamente divulgado, que se refere ao auto reconhecimento dos povos tradicionais, reiteradamente desconsiderada no tratamento do Estado com essas populações no RN.

Um discurso que já deveria ter sido abandonado tem marcado ainda mais o contexto brasileiro atual. Trata-se de uma visão romantizada dos índios que se encontra presa a uma imagem colonial dos índios do passado, como afirmado por Oliveira (2016). Esse é um dos motivos pelos quais a Convenção $n^{0} 169$ da OIT é tão acionada e ao mesmo tempo tão ignorada a ponto de voltarmos a discutir no Congresso Nacional se o Brasil permanece ou deixa de ser signatário desta convenção. Isso nos remete ao texto de Foucault na aula de 14/01/1976, da obra "Em defesa da sociedade", em que o autor se pergunta "quais são as regras de direito de que lançam mão as relações de poder para produzir discursos de verdade? Ou ainda: qual é esse tipo de poder capaz de produzir discursos de verdade que são, numa sociedade como a nossa, dotados de efeitos tão potentes? (1999)". Para o autor, a ação política fabrica o corpo biologicamente falando e gesta a vida e a morte das populações. Essa prática que o autor intitula de biopoder é agravada em situação de pandemia, como é o caso atual.

Não bastasse o desafio cotidiano do Movimento Indígena do Rio Grande do Norte para superação do estigma de "desaparecidos" ainda tão enraizado no estado, em janeiro deste ano, a FUNAl havia publicado a Resolução $n^{\circ}$ 04/2021 (suspensa pelo STF no âmbito da ADPF 709 após provocação da APIB), que se propunha a definir critérios de heteroidentificação de povos e indivíduos indígenas, o que na prática representava uma revisão da Convenção $n^{\circ} 169$ da OIT, sem 0 cumprimento do processo constitucional para tal e sem que sequer tenha sido respeitado o instituto da Consulta Livre, Prévia e Informada exigida para qualquer tomada de decisão administrativa ou legislativa que afete direitos coletivos dos povos tradicionais. Olhando para a realidade do Rio 
Grande do Norte, a implementação dessa resolução, sobretudo no contexto da pandemia do Covid-19, poderia ser usada para legitimar a recusa na concretização de políticas públicas específicas, como a relacionada à saúde, agravando a situação já difícil dos indígenas que sequer vivenciam a plenitude do reconhecimento formalmente garantido pela norma internacional e pela Constituição brasileira. Este é outro aspecto também considerado por Foucault (1999) em seu texto, quando o mesmo afirma que "o sistema do direito e o campo judiciário são o veículo permanente de relações de dominação, de técnicas de sujeição polimorfas. O direito, é preciso examiná-lo, creio eu, não sob o aspecto de uma legitimidade a ser fixada, mas sob o aspecto dos procedimentos de sujeição que ele põe em prática" (p.32).

Outra questão que afeta as populações indígenas do Rio Grande do Norte e apareceu como obstáculo enfrentado pelo Movimento Indígena foi o acionamento das problemáticas categorias "índios aldeados" e "índios desaldeados", ou mesmo "índios urbanos" e "índios rurais", completamente insuficientes para se pensar a realidade indígena, haja vista que essa população está em contínuo movimento entre as cidades e as aldeias, seja por deslocamentos forçados em razão da ausência de demarcação, proteção territorial ou prestação de outros serviços essenciais que impossibilitam sua manutenção no território tradicional, seja temporariamente para acessar outros direitos tais como o acesso à qualificação educacional/profissional, trabalho ou mesmo para articulações políticas, só para destacar algumas dentre infinitas e irrefreáveis possibilidades. Essa população, mesmo quando se encontra em áreas mais distantes dos centros urbanos, vive em contínuo movimento, habitando as cidades mais próximas de suas áreas e reafirmando sua distintividade cultural. Assim, a inadequada separação burocrática entre "índios aldeados" e "índios desaldeados", "urbanos" e "rurais", nega os processos históricos e as necessidades dos povos indígenas, constituindo graves entraves à efetivação dos direitos de uma grande parcela dessa população, como vimos ocorrer, num primeiro momento, com relação à exclusão na imunização prioritária contra à Covid-19 no país inteiro.

E aqui podemos mais uma vez acionar Foucault (1999), quando o mesmo fala sobre o controle do Estado sobre os corpos e as identidades. Há uma efetiva necessidade disciplinadora desses corpos e dessas identidades por parte do Estado. O que Foucault chama de biopolítica, com a sujeição de corpos e controle da população dizendo o que fica dentro e o que está fora da normativa. Vale ressaltar, ainda, que a condição de indígena independe da demarcação territorial, sendo o direito ao usufruto das terras tradicionalmente ocupadas apenas uma parcela das prerrogativas endereçadas aos indígenas pelo direito constitucional vigente. A ausência de reconhecimento do direito fundiário não pode prejudicar outros direitos de envergadura constitucional e infraconstitucional já assegurados à população indígena, sob pena da omissão estatal vulnerabilizar duplamente essa população. A formalização do direito à saúde indígena representa a concretização de um direito fundamental social e o reconhecimento de que os povos 
indígenas merecem tratamento que atenda às suas especificidades socioculturais. Dentro disso destaca-se o direito à imunização prioritária contra a Covid-19, que deve ser garantida à totalidade da população indígena independentemente de onde vivam.

Apesar da inexistência de informações epidemiológicas mais precisas das etnias indígenas do Rio Grande do Norte, em virtude da sua exclusão do Sistema de informação da Atenção à Saúde Indígena, diversos outros dados coletados pelo próprio movimento indígena no estado e documentos analisados nesse artigo, evidenciam as precárias condições de saúde dessas populações, o que coloca em risco sua sobrevivência física e cultural. Uma vez que a saúde, como vimos, é condicionada por diversos fatores sociais, ambientais, culturais, étnicos e econômicos, não há como desconsiderá-los na implementação das políticas públicas, mesmo em contexto de crise sanitária que atinge a população em geral, como no caso da Pandemia pela Covid-19, pois mesmo nessas situações há o agravamento para os grupos sociais mais vulneráveis, dentre os quais estão os povos indígenas.

Apontando essa realidade e reconhecendo o dever do Estado na gestão das políticas públicas para concretização de direitos, o Movimento Indígena no Rio Grande do Norte permanece reivindicando ao poder público, por diversos meios, a reversão da preocupante invisibilidade demográfica e epidemiológica vivenciada por suas populações, com intervenções adequadas para mitigação da situação emergencial vivenciada no atual contexto de pandemia, garantindo a correta implementação da Atenção à Saúde diferenciada, bem como construindo condições que possibilitem uma existência saudável em seu sentido pleno. 
Espaço Ameríndio

\section{Referências bibliográficas}

APIB. Aditamento à Arguição de Descumprimento de Preceito Fundamental $n^{0} 709$, 2021.

ATHIAS, R. Saúde, participação e faccionalismo entre os Pankararu. In: Povos indígenas de Pernambuco: identidade, diversidade e conflito. Recife: ed. Universitária da UFPE, 2007.

BRASIL, Ministério da Saúde. Relatórios do Conselho Nacional de Saúde: Conferência Nacional de Proteção à Saúde do Índio, 1986.

BRASIL, Ministério da Saúde. Relatórios do Conselho Nacional de Saúde: II Conferência Nacional de Saúde para os povos indígenas, 1993.

BRASIL. Ministério da Saúde. Relatórios do Conselho Nacional de Saúde: Conferência Nacional de Proteção à Saúde do Índio, 1986.

BRASIL. Fundação Nacional do Índio. Ofício no 10/2021/CTL - NATAL/CR-NEII/FUNAI, 17 de janeiro 2021. In: BRASIL. Ministério Público Federal. Inquérito Civil $\mathrm{n}^{\mathrm{o}}$ 1.28.000.000709/2020-2. Natal: $12^{\circ}$ oficio PR/RN, 2020.

BRASIL. Lei n ${ }^{\circ} 8080$ de 19 de setembro de 1990.

BRASIL. Lei n ${ }^{\circ} 9836$ de 23 de setembro de 1999.

BRASIL. Ministério da Saúde. Relatórios do Conselho Nacional de Saúde: IV Conferência Nacional de Saúde Indígena, 2006.

BRASIL. Ministério da Saúde. Relatórios do Conselho Nacional de Saúde: II Conferência Nacional de Saúde para os povos indígenas, 1993.

BRASIL. Ministério da Saúde. Relatórios do Conselho Nacional de Saúde: IV Conferência Nacional de Saúde Indígena, 2006.

BRASIL. Ministério Público Federal. Inquérito Civil nº 1.28.000.000709/2020-2. Natal: $12^{\circ}$ oficio PR/RN, 2020.

BRASIL. Tribunal Regional Federal da $5^{\text {a }}$ Região. Ação Civil Pública $n^{0}$ 080039162.2020.4.05.8400. RN: 2020.

BRASIL. Constituição da República Federativa do Brasil, 1988.

CARDOSO, M. Saúde e povos indígenas: equívocos na política atual. Cadernos de Saúde Pública. 2014. 30 (4). p. 860-866.

CASANOVA, P. Colonialismo interno (uma redefinição). A teoria marxista hoje. Problemas e perspectivas. In: Consejo Latinoamericano de Ciencias Sociales (CLACSO) Buenos Aires: Campus Virtual, 2007. p. 431-458. 
CASCUDO, L. C. História do Rio Grande do Norte. Natal: Fundação José Augusto, 1984.

CAVIGNAC, J. A etnicidade encoberta: "indios" e "negros" no Rio Grande do Norte. Mneme, v. 4, n. 8. Natal, 2003.

CHCTPLA. Nota de repúdio. Apodi: Centro Histórico Cultural Tapuias Paiacus da Lagoa do Apodi, 2021. Disponível em: https://www.facebook.com/indiostapuiaspaiacusdoapodi/photos/1806804326192672. Acessado em 28 de maio de 2021.

COIMBRA Jr., C. E. A.; Santos, R. V. Saúde, minorias e desigualdade: algumas teias de inter-relações, com ênfase nos povos indígenas no Brasil. Ciência \& Saúde Coletiva, 5(1):125-132, 2000.

DECLARAÇÃO DE ALMA - ATA. Conferência internacional sobre os cuidados primários de saúde. URSS, 1978.

DIEHL, E; LANGDON, E. J. Transformações na atenção à saúde indígena: tensões e negociações em um contexto indígena brasileiro. Revista Universitas Humanística. 2015. p. 213-236.

DUPRAT, D.; TERENA, L. E. O genocídio indígena atual. Jota, 2021.

FARIAS, I. S. Doenças, dramas e narrativas entre os índios Jeripankó no sertão de alagoas. Maceió: EDUFAL, 2011.

FOUCAULT, M. Aula de 14 de março de 1976. In: Em defesa da sociedade. São Paulo: Martins Fontes, 1999. p. 28.

GARNELO, L. O SUS e a saúde indígena: matrizes políticas e institucionais do subsistema de saúde indígena. In: Teixeira, C.; Garnelo, L. (org.) Saúde indígena em perspectiva: explorando suas matrizes históricas e ideológicas. Rio de Janeiro: Fiocruz, 2014.

GUERRA, J. Identidade Indígena no Rio Grande do Norte: caminhos e descaminhos dos Mendonça do Amarelão. Fortaleza: editora IMEPH, 2011.

KRENAK, A. Ideias para adiar o fim do mundo. São Paulo: Companhia das Letras, 2019.

LANGDON, E. J.; Cardoso, M. D. (Orgs). Saúde Indígena: Políticas comparadas na América Latina. Instituto Brasil Plural: UFSC. 2015.

LANGDON, E. J.; GARNELO, L. Articulación entre servicios de salud y "medicina indígena": reflexiones antropológicas sobre política y realidad en Brasil. In: Salud Colectiva. Universidad Nacional de Lanus. 2017. 13(3). p. 457-470. 
LIMA, N. Municípios do Rio Grande do Norte: Areia Branca, Arez, Assu e Augusto Severo. Edição Fac-Similar da revista do Instituto Histórico do Rio Grande do Norte. v. 25/26 - 1 Edição - 1929. Coleção Mossoroense. Série C - v. DXCV, 1990.

LOPES, F. M. Índios, colonos e missionários na colonização da capitania do Rio Grande do Norte. Mossoró: Fundação Vingt-un Rosado, Instituto Histórico e Geográfíco do Rio Grande do Norte, 2003.

MACEDO, H. A. M. Populações indígenas no Sertão do Rio Grande do Norte: História e mestiçagens. Natal, EDUFRN, 2011.

MEDEIROS FILHO, O. Índios do Açu e Seridó. Brasília: ed. do Senado, 1984.

MEDEIROS FILHO, O. No rastro dos flamengos. Natal: Fundação José Augusto, 1989.

MEDEIROS FILHO, O. Os aldeamentos do Apodi, Serra de Santana e Gramació. O Poti, Natal, cad. 2, p. 2, ago. 1990.

MEDEIROS FILHO, O. Os Tarairiús, extintos tapuias do Nordeste. Mossoró: Fundação Vingt-un Rosado, 1988.

MENDES A. M., LEITE M.S., LANGDON E.J., GRISOTTI M. O desafio da atenção primária na saúde indígena no Brasil. Rev Panam Salud Publica. 2018. p. 42 e184.

MENDONÇA, D. Entrevista, 22 de janeiro de 2021. Entrevistador: Mariella Lopes. Natal: Portal Saiba Mais, 2021.

MENDONÇA, D. Digi-Denúncia, 01 de março de 2021. Manifestação no 20210017928. In: BRASIL. Ministério Público Federal. Inquérito Civil no 1.28.000.000709/2020-2. Natal: $12^{\circ}$ oficio PR/RN, 2020.

MOURA, A. D. M. Aqui tem sangue e suor de índio: resistência, etnicidade e luta política dos tapuias da Lagoa do Tapará - RN, 2019. 213f. Dissertação (Mestrado em Antropologia) - PPGAS, UFRN, Natal, RN, 2020.

OIT. Convenção nº 169 sobre Povos Indígenas e Tribais, 1989.

OLIVEIRA, J. N. V.; VIEIRA, J. G. Emergência indígena no Rio Grande do Norte: Etnohistória, territorialidade e memória na comunidade dos Caboclos de Assú/RN. Caicó: Anais do V encontro estadual de história - ANPUH/RN, 2016.

OLIVEIRA, J. P. O nascimento do Brasil e outros ensaios. Rio de Janeiro: Contra Capa, 2016.

PEREIRA, M. G. N. Potiguara de Sagi: da invisibilidade ao reconhecimento étnico. 2015. 207f. Dissertação (Mestrado em Antropologia Social). PPGAS, UFRN, Natal, RN, 2015.

PRECIADO, Paul. Aprendiendo del virus. In: Sopa de Wuhan. Editorial Aspo. 2020. p. 163-185 
Espaço Ameríndio

RAMOS, A. R. (org). Constituições nacionais e povos indígenas. Belo Horizonte: editora UFMG, 2021.

SANTOS JÚNIOR, V. Os índios Tapuias do Rio Grande do Norte: antepassados esquecidos. Mossoró: Fundação Vingt-un Rosado, 2008.

SILVA, C. M. M. Em busca da realidade: a experiência da etnicidade dos Eleotérios (Catu/RN). 2007. 281 f. Dissertação (Mestrado em Antropologia Social) PPGAS, UFRN, Natal, RN 2007.

SOUZA LIMA, A. C. Sobre a tutela e participação: povos indígenas e formas de governo no Brasil, séculos XX/XXI. MANA 21(2): 425-457, 2015.

VILLARES, L. F. Direito e povos indígenas. Curitiba: Juruá, 2009.

Recebido em: 31/05/2021* Aprovado em: 09/07/2021 * Publicado em: 30/08/2021 